\title{
Influence of operating conditions and atomizer design on circumferential liquid distribution from small pressure-swirl atomizer
}

\author{
Milan Malý, ${ }^{1, *}$, Lada Janáčková, Jan Jedelský and Miroslav Jícha ${ }^{1}$ \\ ${ }^{1}$ Brno University of Technology, Faculty of Mechanical Engineering, Energy Institute, Technická 2896/2 Brno 616 69, Czech Republic
}

\begin{abstract}
The spray symmetry is an important aspect in most practical applications. However, it is often an overlooked parameter. A measurement of circumferential distribution was carried out by a circular-sectored vessel on several pressure-swirl atomizers with spill-line over a wide range of injection pressure. The obtained results show that the spray uniformity improves markedly with the injection pressure. The increase in a number of tangential entry ports has only a minor effect on the spray uniformity. Even a small mechanical corruption of the atomizer internal parts negatively affects the spray patternation.
\end{abstract}

\section{Introduction}

The symmetry of spray pattern produced by the atomizer is an important parameter in many applications. E.g.: non-uniformities in circumferential fuel distribution in gas turbine combustors can lead to a rise of local pockets of the low fuel-air mixture in which burning rates are low, thereby produce high concentrations of carbon monoxide and unburned hydrocarbons. Moreover, it may lead to non-uniform flame distribution and eventually to local overheating of the combustion chamber. The reasons for spray a non-uniformity are all different: asymmetrical design of the atomizer, uneven size of the inlet ports, poor surface finish. Geometrical dimensions of various parts and operating regimes also affects the spray symmetry.

The number of publications related to the spray patternation is surprisingly low; probably the most complex study was carried out in 1993 by Chen and Lefebvre [1]. They investigated several simplex atomizers with various swirl chamber geometries. Khavkin [2] summarized possible reasons of the spray asymmetry of simplex atomizers.

This study investigates several simplex atomizers differing in the swirl chamber shape and the number of the tangential inlet ports, and more over two spill-return atomizers are also represented in tests. The spill-return atomizers differ due to the presence of a passage in the back wall of the swirl chamber. Liquid, injected via tangential ports into the swirl chamber, is divided into two streams, one of them is discharged outside and atomized while the second is spilled back to a reservoir. This feature greatly expands a turn-down ratio of these atomizers compared to the simplex atomizers, because the liquid is always supplied to the swirl chamber at high pressure guaranteeing a good atomization at various injection flow rates. No relevant literature dealing with the patternation of the spill-return atomizers was found.

\section{Experimental setup}

Experiments were performed at a specially designed facility for cold spray testing in Spray laboratory at the Brno University of Technology.

\subsection{Tested atomizers}

Six simplex and two spill-return atomizers conformed to the schematic drawing in Figure 1 were used in this study, all had the same total area of the inlet ports, $A_{p}=0.72 \mathrm{~mm}^{2}$, and the diameter of the exit orifice, $d_{o}=0.42 \mathrm{~mm}$. Four different swirl chambers differed in the shape of the convergent part - see Figure 2. The shapes under study were as follows: A - hemispheric, B conical; C - curved convex and D - flat conical. In addition, simplex atomizers with two (S2), three (S3) and four (S4) inlet ports were used. Two spill-return atomizers with spill-line in a different position were used as well: SA - axially-positioned, SB - off-axis spill orifices.

\subsection{Test bench and mechanical patternator}

The tested liquid was supplied to the atomizer by a specially designed fuel supply track (schematic layout in Figure 3). The liquid, stored in the fuel tank (1), was pumped via a filter (2) by a gear pump (3) to the atomizer (8). The liquid mass flow rate was regulated by driving the pump speed. The amount of pumped fuel was measured in the inlet line by a Coriolis mass flow meter (4). Liquid overpressure was measured by a piezoresistive sensor (7). The inlet line was also equipped

\footnotetext{
${ }^{*}$ Corresponding author: milan.maly@,vutbr.cz
} 
with a temperature reading. The spill-line was equipped with a static pressure meter (9), regulating needle valve (11) and the positive displacement flow meter (10).

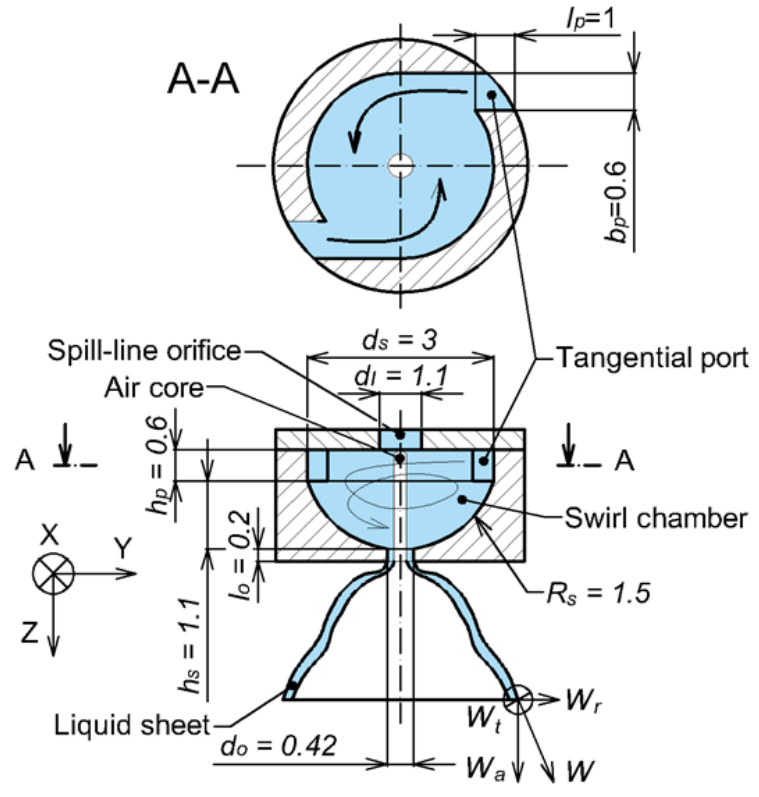

Fig. 1. Schematic layout of tested atomizer
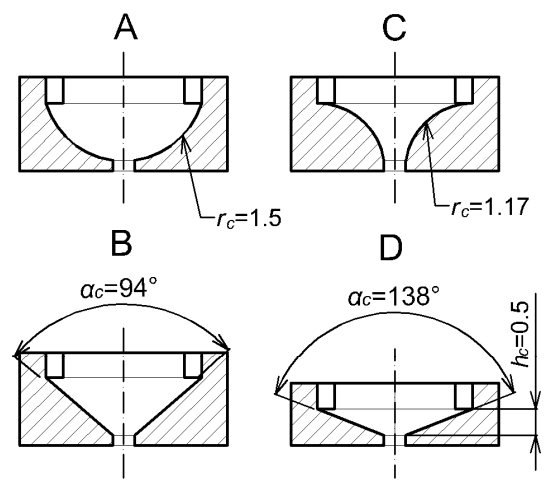

SA

SB
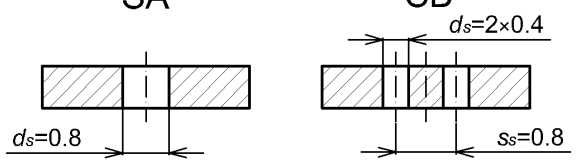

Fig. 2. Schematic drawings of tested variants

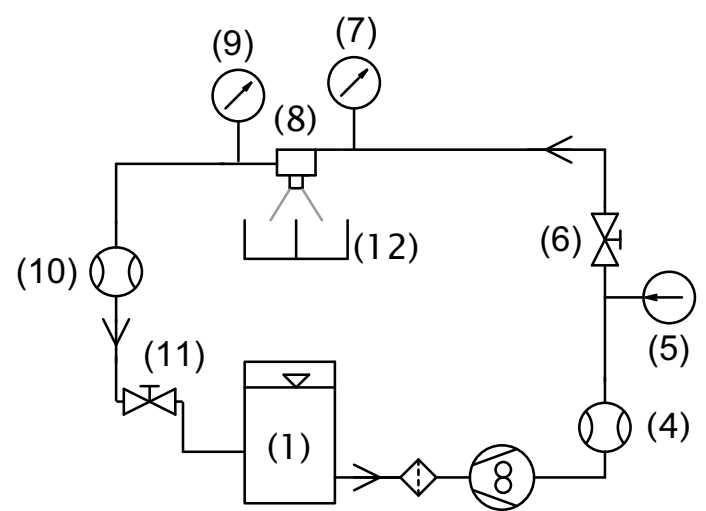

(2) (3)

Fig. 3. Schematic layout of the test bench
The spray circumferential distribution was rated by a simple circular-sectored vessel (12), often called a mechanical patternator, with 16 pie-shaped sectors, as shown in Figure 4. The patternator was placed $50 \mathrm{~mm}$ downstream from the exit orifice of the measured atomizer. The volume of each sector was $60 \mathrm{ml}$. The duration of each test was determined by the time required for one of the sectors to become nearly full. Usually, it was between two and four minutes. The height of the liquid from the upper edge in each sector was measured with a caliper, and the liquid height was calculated. These values were consequently averaged to get the mean height, and the levels of the sectors were normalized against the mean height. The standard deviation of normalized values was calculated as a single parameter describing the non-uniformities:

$$
\sigma=\sqrt{\frac{\sum_{i=1}^{n}\left(y_{i}-\bar{y}\right)^{2}}{n}}
$$

where $n$ is the number of sectors (16), $y_{i}$ is the normalized height of the liquid in sector $\mathrm{i}$ and $\bar{y}$ is the liquid average height.

Jet-A1 fuel was used as the tested liquid. Physical properties of the Jet-A1 at room temperature $\left(20^{\circ} \mathrm{C}\right)$ were: $\sigma=0.029 \mathrm{~kg} / \mathrm{s}^{2}, \quad \mu_{l}=0.0016 \mathrm{~kg} /(\mathrm{m} \cdot \mathrm{s}), \quad \rho_{l}=795$ $\mathrm{kg} / \mathrm{m}^{3}$.

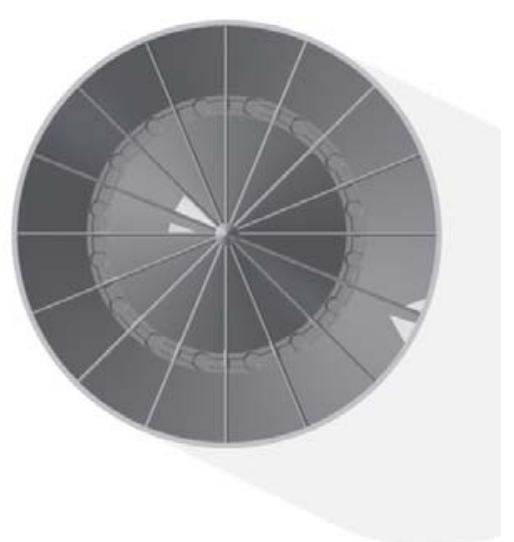

Fig. 4. Mechanical patternator

\section{Results and discussion}

Each atomizer was tested at three pressure regimes, the atomizers with the spill-line were also tested at three spill regimes at constant inlet pressure. Each regime was measured several times, and data consequently averaged.

\subsection{Number of tangential ports}

The effect of the number of the tangential inlet ports is shown in dependence on the circumferential position in Figure 5 and its standard deviation along the three pressure regimes is plotted in Figure 6. The data presented in Figure 5 are typical of the results obtained. 


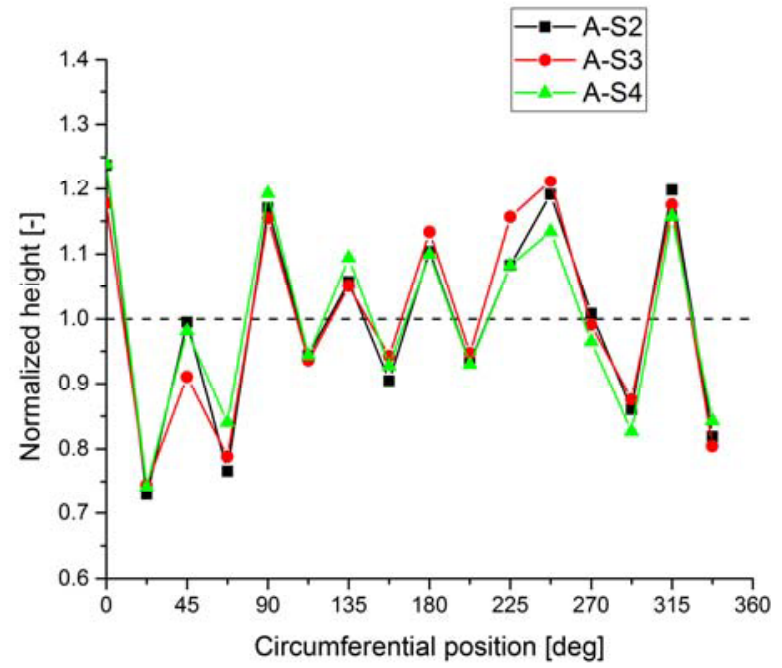

Fig. 5. The liquid distribution from the simplex atomizers with various tangential ports number, inlet pressure $1 \mathrm{MPa}$.

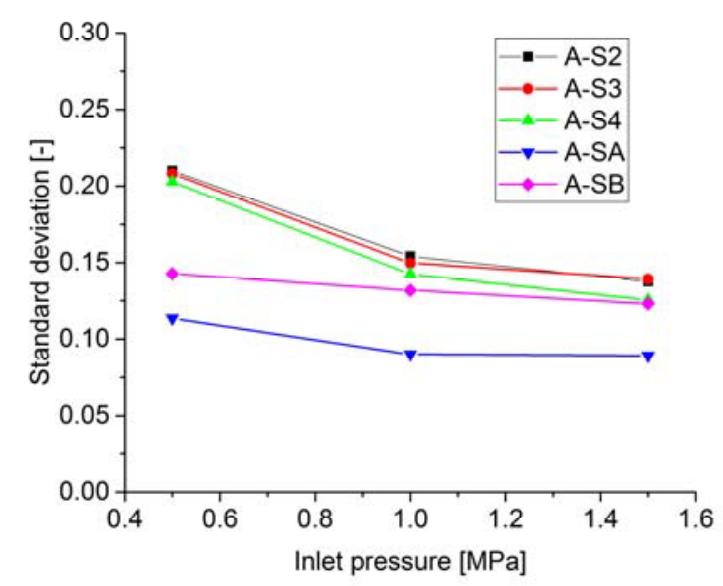

Fig. 6. The influence of tangential ports number and presence of spill-line orifice. Spill-to-Feed ratio (SFR) 0.

However, in this particular example, the atomizers have almost identical behaviour, even if the number of tangential ports is changed. The change in the standard deviation is almost negligible, an increase in a number of the ports from two to four enhances the standard deviation by less than $10 \%$. Similar results were obtained by Chen and Lefebvre [1]. They found the difference in spray patternation between the two and three-port atomizers as insignificant; however, the oneport atomizer under their test had a noticeably rougher liquid distribution. As it is obvious from Figure 6, the increasing liquid pressure has a beneficial effect for all atomizers in terms of liquid distribution.

Different results were obtained with the spill-return atomizers (SA and SB). They are the two-port types but their liquid distribution shows better results compared to the simplex S2. SB with the off-axis spill-orifices has the standard deviation converging to the simplex type at higher pressures. However, SA shows the most uniform spray pattern. This atomizer, the only one in this study, has a visually unstable spray in the same way as it was described in [3]. Because of the long-time measurement compared to the spray fluctuating frequency (which was about $5 \mathrm{~Hz}$ ), data from the patternator are time-averaged and the spray may be not so symmetrical in the short time observation. However, when the spill is applied, the unstable atomizer turns into the stable one at approx. spill to feed ratio (SFR) of 0.1. For SFR higher than 0.1, the SA atomizer becomes stable and results are not distorted by the spray fluctuations. The influence of SFR on patternation at constant inlet pressure of $1 \mathrm{MPa}$ is shown in Figure 7. Increasing SFR has a positive effect on the droplet size [4] but circumferential distribution rapidly worsens. This behaviour was observed for both spill-return atomizers; their standard deviation reaches almost an identical value at SFR 0.4. Patternation rapidly deteriorates with further increases in SFR over 0.4. This phenomenon may be related to the decreasing discharge velocity with increasing SFR. The droplets are migrating from one sector to another with lower activity, and thus the atomizer is more sensitive to any imprecisions.

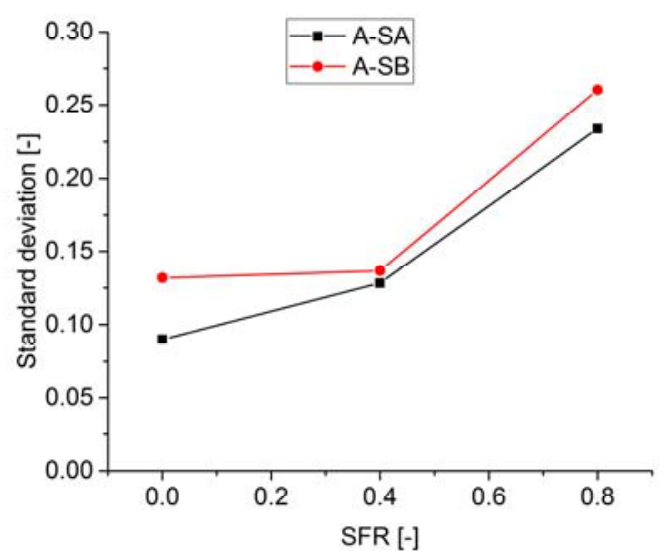

Fig. 7. The influence of the spill regime on patternation at inlet pressure of $1 \mathrm{MPa}$

\subsection{Influence of swirl chamber shape}

Four swirl chambers were tested in the three-ports simplex atomizer. Results, presented in Figure 7, show a considerable influence of the swirl chamber shape on the spray patternation. The most uniform distribution was accomplished by the high conical chamber B. The chamber with the lower convergent part (D) has about $25 \%$ higher standard deviation which is almost undependable on the inlet pressure. A similar characteristic was observed in the curved convex chamber-C. Unlike to the C and D chambers, patternation of the hemispheric chamber A strongly depends on the inlet pressure.

\subsection{Mechanical corruption of the atomizer}

Apart from the atomizer design itself, geometrical inaccuracies, surface quality, and mechanical corruptions have an impact on the spray uniformity $[1,2,5]$. These problems were discussed in the appointed literature. However, impact of manufacturing quality was described only theoretically. 


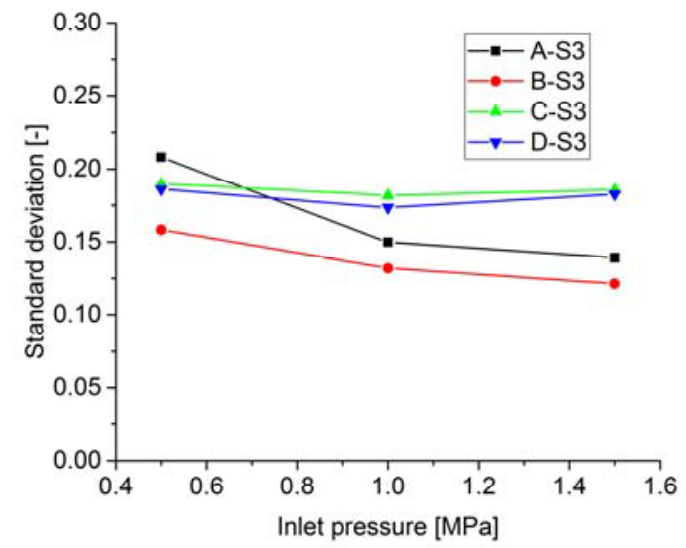

Fig. 8. The influence of the swirl chamber shape
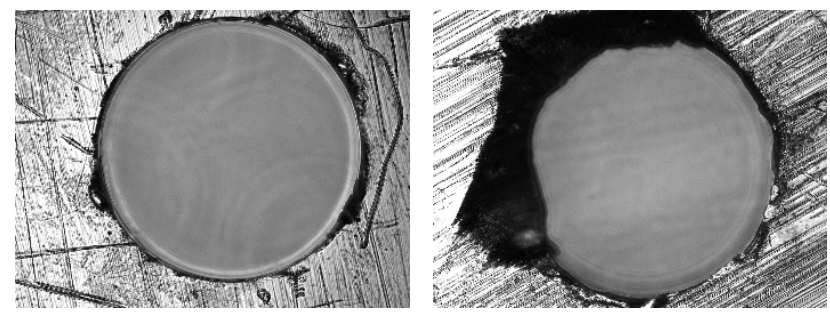

Fig. 9. Left: fine exit orifice, right: damaged exit orifice

Due to a difficult assessment of the surface quality and geometrical accuracy of the atomizer itself, this part focuses primarily on the mechanical corruption of the atomizer parts.

In this paper, two atomizers damaged by mishandled installation are investigated, the first one has a minor mechanical corruption of the exit orifice while the second one has a corrupted tangential port. They are compared to the identical types of regular shape. A geometrical difference between the corrupted and original exit orifice is shown in Figure 9; the original part is on the left, the corrupted one on the right. The images were taken using an optical microscope Nikon Eclipse E200. The depth of the scratch is approximately $0.1 \mathrm{~mm}$. The tangential port was damaged at its exit cross-section and the liquid flow may be deflected from original direction.

The scratch on the outer edge of the exit orifice caused an increase in the standard deviation by $86 \%$. The atomizer with corrupted tangential port has almost 3 times higher standard deviation compared to the fine one.

\section{Conclusions}

The experimental investigation was undertaken to study the effect of several parameters on the spray uniformity. Besides simplex atomizers, spill-return types were also presented in this study.

- The circumferential uniformity of spray pattern improves with increasing liquid pressure for the most of the tested atomizers.
- An increase in the number of the tangential ports from two to three or four has a negligible effect.

- The shape of the swirl chamber convex part contributes greatly to the spray uniformity.

- The unstable atomizer has a more uniform spray in the long-time measurement than the stable one.

- Poor finish quality or mechanical damage of the exit orifice or the inlet tangential ports deteriorate the spray symmetry.

\section{Acknowledgement}

This work has been supported by the project No. GA1509040S funded by the Czech Science Foundation, the project LO1202 NETME CENTRE PLUS with the financial support from the Ministry of Education, Youth and Sports of the Czech Republic under the "National Sustainability Programme I" and project Reg. No. FSI-S14-2355 funded by the Brno University of Technology.

\section{References}

1. S. Chen, A. Lefebvre, J. Rollbuhler, J. of eng. for gas turbines and power, 115, pp. 447-452. (1993)

2. Y. Khavkin, The Theory and Practice of Swirl Atomizers (2004)

3. M. Maly, L. Janackova, J. Jedelsky,M. Jicha, EPJ Web of Conferences (2016)

4. J. Jedelsky, M. Maly, L. Janackova, M. Jicha, ILASS p. 12 (2016)

5. A. H. Lefebvre, Atomization and sprays (1989) 